\title{
Historia de las mentalidades: posibilidades actuales
}

Carlos Barros

Universidad de SANTIAgo de Compostela

$\mathrm{L}$

a propia vastedad del campo de investigación que se dice abarca en este momento la historia de las mentalidades dificulta una definición que tampoco sea quizás conveniente hacer en su sentido más estrecho y formal, por aquello de que las definiciones son como las cárceles... y que no hay nada más estéril que enredarse en una discusión sobre la definición convencional de una noción que hace referencia a algo tan extenso como la mente humana en la historia. Pero, en todo caso, si queremos entendernos hay que delimitar de alguna manera el territorio de la historia de las mentalidades. Rigiéndonos por la propia práctica investigadora, y sin pretensiones de hallar la fórmula feliz que todo lo aclara, propondremos algunos elementos definitorios cuya eficacia científica dependerá sobre todo de la ayuda concreta que puedan prestar para la indagación y la comprensión de las mentalidades históricas.

\section{LA MENTALIDAD GLOBAL}

Y SUS COMPONENTES

Definiendo el todo por las partes, y buscando una relativa convergencia del objeto de la historia de las mentalidades con objetos de las diferentes ramas de la psicología en cuanto ciencia social, interesa distinguir cinco componentes en la mentalidad: 1) lo racional, 2) lo emotivo, 3) lo imaginario, 
4) lo inconsciente y 5) la conducta. Los cuales corresponden a distintos modos de percibir la realidad y/o de actuar sobre ella; se mezclan y superponen unos con otros, de forma que cada función o manifestación mental aparece coloreada por un(os) componente(s) más que otro(s), mezclado(s) químicamente: el todo no se reduce a la suma de los componentes. Las mentalidades que más pueden concernir al historiador de una historia explicativa que persigue totalidades protagonizadas por colectivos, raramente equivalen a una relación psicológica elemental de los sujetos con su entorno, pues son mentalidades globales a menudo intrincadas, de difícil discernimiento cuando no se han aclarado antes las formas mentales más sencillas y básicas.

Vayamos con el primer componente. Dentro del estudio de lo racional habría que encuadrar la historia cultural e intelectual de las ideas y de la filosofia; $y$ en el terreno estrictamente de la historia social, la exploración de la conciencia. ${ }^{1}$ Bajo la influencia primero de la antropología orientada hacia el estudio de las cultu. ras primitivas, ${ }^{2}$ y después de la psicología interesada por la vida mental

1 Los investigadores soviéticos de la conciencia social han llegado a una conclusion que a su vez justifica la necesidad de un concepto más amplio como mentalidad: la conciencia de un todo volumétrico y pluridimensional, la parte del iceberg que está en la superficie. Y se la debe examinar junto con sus partes ocultas y, en dependencia de ellas, partes ocultas que incluyen lo inconsciente y lo simbólico, Mamardashvili, "Análisis", 1987, p. 133.

2 Levy-Bruhl, Fonctions, 1910; Levy-Bruhl, Mentalite, 1922. de los niños, ${ }^{3}$ la noción de mentalidad fue recogida por Marc Bloch y Lucien Febvre a principios de siglo y aplicada a la historia, justamente con la finalidad de aprehender las funciones psíquicas que, cayendo fuera del pensamiento lógico, explican no pocos comportamientos colectivos. Norbert Elias resume su investigación sociopsicológica sobre el tránsito a la modernidad y a la civilización, planteando como problema general del cambio histórico el que "este cambio en su totalidad no está planificado ractonalmente", y añade:

Es impensable que el proceso civilizatorio haya sido iniciado por seres humanos capaces de planificar a largo plazo y de dominar ordenadamente todos los efectos a corto plazo, ya que estas capacidades, precisamente, presuponen un largo proceso civilizatorio. ${ }^{4}$

Esta es la cuestión, el historiador no puede trasladar a épocas pretéritas formas de pensar y de actuar que han sido el resultado de siglos de historia. Un concepto como el de mentalidad que al mismo tiempo incluya y supere al pensamiento racional, la conciencia y la ideología, en caso de que no existiera, habria desde luego que inventarlo para investigar con rigor la acción humana en la historia.

Lo emotivo, 5 elevado a objeto de investigación histórica en el cuadro de la historia de las mentalidades, comienza sin duda, en 1932, cuando

3 Wallon, Mentalite, 1928.

- Elias, Proceso, 1987, p. 451.

5 Duvignaud, Gendse, 1990. 
Georges Lefebvre publica La grande peur de 1789. Marc Bloch titula en 1939-1940 un capítulo de La soctété féodale, "Formas de sentir y de pensar". Lucien Febvre, a su vez, en los años cincuenta publica varios trabajos, usualmente en Annales, donde esboza las características de una historia de los sentimientos y la sensibilidad, adelantando y animando temas como el terror, la muerte y el sentimiento de seguridad. ${ }^{6} \mathrm{La}$ última aportación de la historiografia francesa -la más fructífera todavía en la historia de las mentalidades $-{ }^{7}$ son las obras de Jean Delumeau sobre el miedo y la seguridad en la baja edad media y la edad moderna. ${ }^{8}$

Existe un sector de las mentalidades colectivas ocupada por la imaginación en cuanto capacidad mental que interviene en los procesos de conocimiento que estimula en tal medida la acción humana, que su toma en consideración por parte de la historiografia más renovadora, bastaría para justificar el salto epistemológico de una historia de las ideologías a una historia de las mentalidades. ¿Qué entendemos entonces por imaginario??

6 Febvre, "Histoire", 1951, "Mort", 1952, "Sensibilite", 1953, "Peur", 1956; trabajos recientemente reeditados en una obra colectiva, Sensibilite, 1987.

7 Las últimas reformulaciones y ampliaciones de la historia de las mentalidades en Francia como antropología histórica y como historia cultural remiten ya obligatoriamente a los historiadores anglosajones, antiguos exploradores de estos territorios.

8 Delumeau, Peur, 1978, Rassurer, 1989.

9 Sobre el concepto de imaginario y la historia de 10 imaginario: Patlagean, "Histoire", 1978; Castoriadis, Institution, 1975; Joutard,
El conjunto de las representaciones mentales -ante todo reproducciones gráficas: imágenes- por medio de las cuales los hombres reconstruyen un mundo interior distanciado de la realidad material, que deviene así en realidad inventada. Ia historia de las mentalidades como historia del imaginario, que ha tomado, en primer lugar de la antropología, métodos para analizar imágenes y símbolos, ${ }^{10}$ además de echar mano de la historia del arte $y$ de la literatura y de sus fuentes específicas, se concentra últimamente en el estudio de las representaciones sociales, ${ }^{11}$ noción utilizada por los historiadores en su expansión actual hacia la psicología social, 12 lo que prueba una renovada alianza entre historia y psicología. El concepto de representación social ensancha, pues, el dominio original de lo imaginario como mero simbolismo, facilita la conexión de las representaciones mentales con las totalidades sociales y la utilización de todo tipo de fuentes históricas, además de las iconográficas y literarias, con el fin de investigar el imaginario colectivo. ${ }^{13}$ Un tema historiográfico donde predomina el componente imaginario de la mentalidad es, por ejemplo, la representación so-

"Histoire", 1978, pp. 38-42; Backzko, Imaginaires, 1984; Le Goff, Imaginarie, 1985; Schmitt, "Introducción", 1986, pp. 16-33, Image, 1987.

10 Un libro de antropología cultural útil a este respecto: Sperber, Simbolismo, 1978.

11 Incluso la expresión bistoire des menta. lites es sustituida por bistoire des representations por parte de algunos autores franceses.

12 Jodelet, Representations, 1989.

13 Un ejemplo próximo a la historia política es la obra colectiva Mentalttes, 1989. 
cial del rey, que ha dado ya pie a una importante bibliografia. ${ }^{14}$

Pero hay un factor psicológico cuya intervención en la historia humana es negada con más fuerza por el historiador positivista: lo inconsctente. ${ }^{15}$ Reticencias que a menudo son, paradójicamente, inconscientes: ¿quién puede negar conscientemente la irreversibilidad de la revolución científica de Freud, descubridor de la importancia de los procesos mentales que actúan sobre la conducta y escapan a la conciencia? Cuestión aparte son las dificultades metodológicas que se presentan para la verificación empírica de hipótesis basadas en prácticas inconscientes, ${ }^{16}$ que no obstante contribuyen a descifrar hechos y problemas históricos, cuya comprensión global resulta impermeable a un enfoque más tradicional.

La aplicación de los descubrimientos de Freud a la historia tuvo entre sus primeros seguidores a freudomarxistas como Wilhelm Reich y otros. ${ }^{17}$

14 Block, Rois, 1962; Kantarowicz, Cuerpos, 1985; Erlande, Roi, 1975; "Royaute", 1984, pp. 429-453; Geisley, Roi, 1987; Boureau, Simple, 1988 ; Berce, Roi, 1990.

15 Flottes, Inconsciente, 1971; Vovelle, "Inconsciente", 1985.

16 En todo caso no mucho mayores que en las existentes para comprobar el resto de la hipotesis; normalmente las actuaciones inconscientes no se producen solas, al margen de la conducta intencional, y las huellas documentales que dejan los comportamientos conscientes permiten establecer las relaciones y verificaciones pertinentes, de modo que la explicación de la mediación inconsciente se puede demostrar a menudo por exclusión.

17 Reich, Psicologia, 1973; una panorámica general sobre el freudomarxismo en Munne, Psicologias, 1982, pp. 69-177.
Pierre Vilar sigue este mismo camino en su última obra sobre los nacionalismos para una colección histórica que, dirigida por Jacques Le Goff, se publicará simultáneamente en varios países europeos. Por otra parte, existe toda una corriente historiográfica norteamericana (que hasta el día de hoy no ha tenido mucho eco en Europa ${ }^{18}$ ), la psicohistoria, ${ }^{19}$ que promueve el estudio de la historia por medio de las categorías psicoanalíticas y que alimenta dos revistas: The Psychohistory Revlew, dentro del ámbito de la Asociación Nacional de Historiadores, y Psychobistory Review. The Journal of Psycbobistory, fundada por Lloyd de Mause, y menos preocupada por la aceptación académica de dicha disciplina. Resta añadir que quizás la técnica psicohistórica que suscita más recelos de los historiadores de profesión sea la empatía, el uso abusivo de la institución para, ubicándose el autor en el lugar del sujeto histórico, acceder a la realidad de "lo que sucedió realmente". 20

Como quinto componente de la mentalidad tenemos a la conducta: lo que el hombre hace -que incluye lo que dice, es decir, al lenguaje. En sentido estricto, plenamente conductista, la actividad humana observable

18 La colección de textos recogida y comentada por Besançon, Histoire, 1974, fue una iniciativa que ni siquiera por parte de su iniciador tuvo continuidad.

19 Binion, Introducción, 1986; Szatula, Psycbobistoire, 1987; Lloyd de Mause, Blbliography, 1975, Foundations, 1982; Gilmore, Psycbobistorical, 1984; M. Kren y H. Rappaport, Varietes, 1985; desde un punto de vista más crítico, Friedlander, Histoire, 1975.

20 Friedlander, Histoire, 1975. 


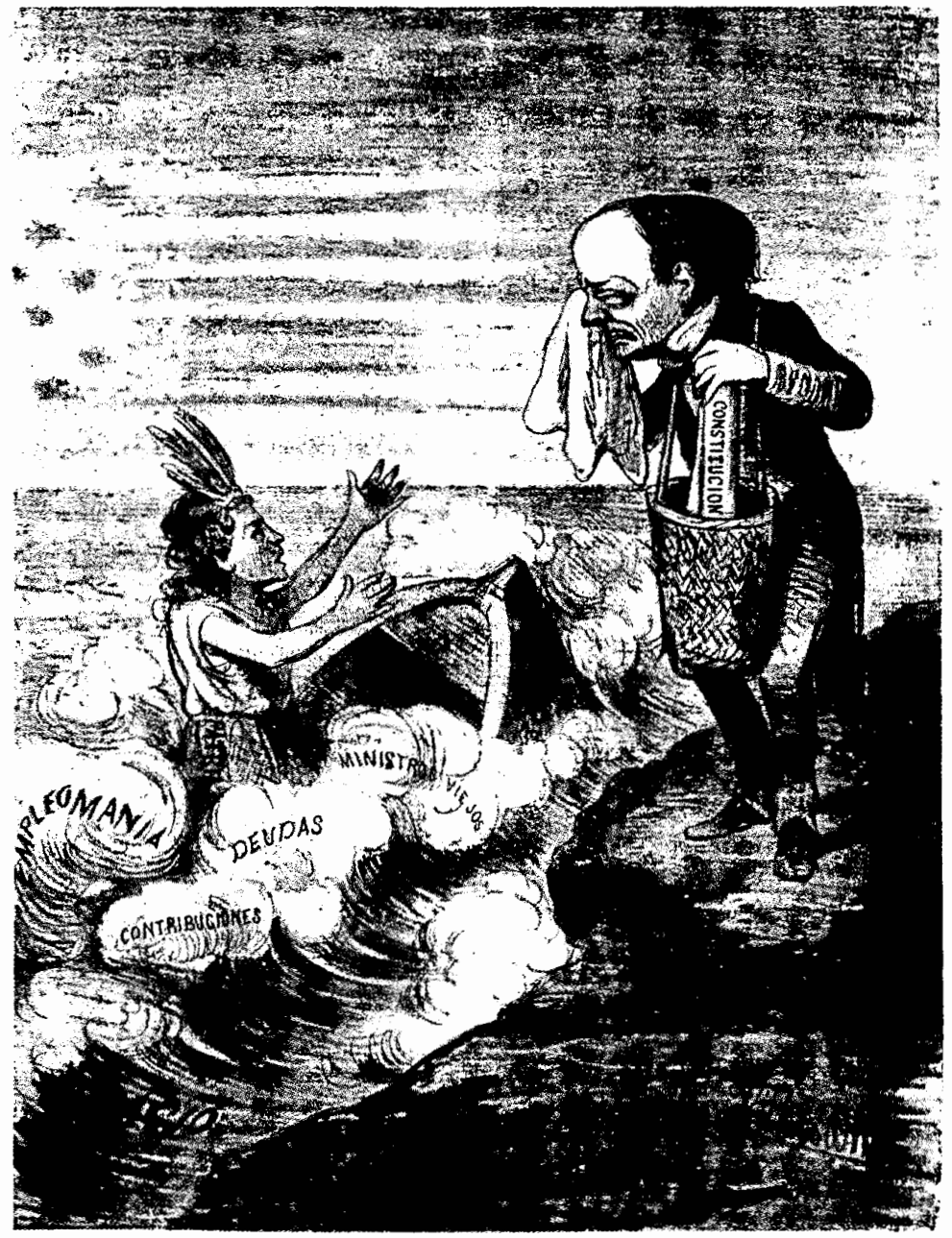

- Siots contar de un naufrago la hetorra,

Ya-que en la terra hasta el amor se oloridas

itencontrará un sepulcro mi memorias

-j.Aqw' La guardare' lada mi vida'...... 
no forma parte de la experiencia interior, mental, pero la necesaria convergencia de la historia de las mentalidades con las demás disciplinas vecinas, más experimentadas en la investigación de la psique humana, nos estimula a no desdeñar ningún campo de investigación que lo sea de la psicología científica en sus distintas tendencias, a saber: psicología conductista, psicología cognitiva y psicología analítica (psicoanálisis), sin ignorar que el mayor grado de identidad en cuanto al objeto tiene lugar entre historia y psicología cognitiva, y muy especialmente entre historia social y psicología social. Por lo demás, la inclusión de comportamientos colectivos en territorios de la historia de las mentalidades, permite un mayor intercambio de ésta con la antropología histórica (interesada en el lenguaje gestual ${ }^{21}$ y los rituales, el juego y la tradición, ${ }^{22}$ por ejemplo) y con la nueva historia sociocultural, y en general la concordancia de la tendencia creciente de las ciencias sociales con el estudio de prácticas sociales, culturales y privadas. ${ }^{23}$ Así, conforme el territorio de la historia de las mentalidades se ha ido ampliando, los objetos estudiados guardan menos relación con lo puramente mental y tie-

21 Tema antropológico investigado históricamente en una obra reciente: Schmitt, Raison, 1990.

22 Hobsbawm y Ranger, Invent, 1988.

23 Bordieu, Esquisse, 1972; Foucault ha influido en la investigación de la vida privada desbrozando el campo de las "prácticas de sín", el trabajo sobre sí mismo por el que los seres humanos se constituyen como sujetos. Vázquez, Foucault, 1988, p. 158. nen más que ver con ese dominio epistemológicamente menos limitado que es la subjetividad humana.

Destaquemos de la actividad práctica de los hombres tres temas historiográficos, entre los muchos posibles y cuya explotación puede ser -mejor dicho, está siendo ya-productiva: el vocabulario, ${ }^{24}$ la vida cotidia$\mathrm{na}^{25}$ y la violencia. ${ }^{26} \mathrm{La}$ investigación histórica de la violencia sigue en la actualidad tres direcciones principales: la violencia cotidiana a la manera de la antropología social, ${ }^{27}$ la violencia como criminalidad y como represión -que entronca con una historia renovada de la justicia y del derecho-28 y la violencia colectiva -cuyo estudio

24 Dupront, "Semantique", 1969; Dupront, "Langage", 1970; Furet y Fontana, "Histoire", 1970; Robin, Histoire, 1973; Chevalier, "Lengua", 1980; Molho, "Linguistique", 1976; Labrousse, Ordenes, 1978; Cerquiglini, "Linguistique", 1986.

23 Sobre este tema de origen etnolbgico, como en cualquier otro dominio histórico que se nos ocurra, se puede hacer una historia buena o mala, anecdótica o seria, descriptiva o explicativa, etc. Verbigracia: Aaron Gurevicht, en un incisivo artículo sobre ciencia histórica y antropología histórica resalta el momento de la innovación de la vida diaria, en la economía y en la existencia cotidiana, como un plano fundamental para comprender los cambios históricos (Ciencias Sociales, núm. 1, 1991, p. 148); refe. rencias bibliográficas: Lefebvre, Critique, 1946 1.981; Le Goff, "Historiador", 1983; Wolfromm, "Quarenta", 1986, "Sociología", 1984; Wickham, "Comprender", 1989.

26 Chesnais, Histoire, 1981; Raynaud, Violence, 1990.

27 Girard, Violence, 1972; Chiffo-Leau, "Violencen, 1980; Farge, Vie, 1986; Muchambled, Violence, 1989.

28 Foucault, Vigilar, 1990; Spierenburg, Judicial, 1978; Ruguiero, Patrici, 1982, "Violences", 1989; Gasparri, Crimes, 1989, "Violencia", 1990. 
añade una nueva dimensión a la historia de los conflictos, las revueltas y las revoluciones. ${ }^{29}$

La actividad humana, desde las palabras y los gestos hasta los grandes hechos colectivos y personales, entra en el campo de la historia amplia de las mentalidades, reformulada como historia subjetiva, por partida doble: constituye el aspecto práctico de la psicología, la conducta, y es, además de ello, una fuente capital para el estudio de la mentalidad en su conjunto. ${ }^{30} \mathrm{Cada}$ acto humano viene acompañado del entorno mental que forman sus motivaciones, sus conexiones con otros actos, sus consecuencias. Partiendo de las acciones, podemos llegar por tanto a su contexto psicológico. Ningún otro componente de la subjetividad detenta tan claramente la doble función de la práctica: a la vez objeto y sujeto, fuente y tema de la investigación.

Definiendo pues la mentalidad como la manera de pensar, de sentir, de imaginar y de actuar, nos aproximamos analíticamente a una realidad subjetiva que se presenta en la realidad, según ya dijimos, como una mezcla química de esos cuatro y aun de otros elementos simples más, que constituyen en suma un sistema mental. Precisemos que la mentalidad que busca el historiador en la sociedad del pasado suele ser global desde cuatro puntos de vista: a) Formas mentales complejas ${ }^{31}$ como la memo-

29 Martines, Violence, 1972; Tilly, "Revolu. tions", 1975; Moreta, Malbechores, 1978, Violence, 1990.

${ }^{30}$ Las acciones hablan más alto que las palabras, Burke, Cultura, 1991, p. 127.

31 En todas las manifestaciones psíquicas ria, las actitudes, las creencias o los valores. b) Mentalidades en función de un tema: tiempo, espacio, naturaleza, trabajo, poder, institución, acontecimiento, revuelta, propiedad, dinero, justicia, igualdad, naturaleza, locura, vida, muerte. c) Mentalidades en función de un sujeto: individuo, estamento, clase, profesión, género, grupo de edad, minoría, nación, civilización. d) Mentalidades en función de un periodo temporal concreto.

Sobra decir que el objeto específico de la investigación histórico-psicológica resulta de las combinaciones más diversas. Ejemplos hipotéticos: la creencia en una institución por parte de los habitantes de un país en un momento dado de su historia, las actitudes hacia un acontecimiento de una colectividad definida por un ámbito y un tiempo determinados o la evolución del imaginario igualitario dentro de una clase social en la larga duración.

Por otra parte, a medida que la historia de las mentalidades se desarrolla y ramifica hasta su difusión (todavía no es el caso de España), se imponen síntesis de los resultados de la investigación, ${ }^{32}$ balances y si es preciso rectificaciones, teniendo en mente una historia de las mentalidades que ayude a entender los grandes y pequeños acontecimientos del pasado a partir de la subjetividad hu-

encontramos varios tipos de percepción de la realidad, sólo que en algunas esa diversidad y su articulación es más simple que en otras; se trata también de un problema de grado.

32 La historia de la vida privada que han dirigido Duby y Ariès, con notable exito de público, sobre todo en España, es una tentativa en esa dirección. 
mana, sin olvidar las conexiones de ésta con la historia objetiva de la base material de la sociedad. Quizá lo que conviene en historia no es tanto describir -sea la economía, la política, la mentalidad-como explicar relaciones del tenor siguiente: subjetivo/objetivo, mental/material, corta/larga duración, cambio/estructura, etcétera.

\section{LAS FUENTES Y EL MÉTODO}

A diferencia de otras disciplinas históricas, como la historia económica o la historia política, que tienen más o menos sus fuentes específicas, las fuentes de la historia de las mentalidades son todas las fuentes históricas. Incluso la ausencia de fuentes y de datos (lo no dicho, los silencios cargados de significado) devienen en fuente para el estudio de lo mental colectivo. Siendo relevantes para el historiador de las mentalidades, tanto los testimonios de personas como los hechos de que informan las fuentes. Las acciones humanas, según vimos, son también una fuente para inferir la mentalidad.

Amplitud de fuentes que viene a ser consecuencia de la amplitud de la temática: la subjetividad humana. La novedad epistemológica que aportan al conocimiento histórico la historia de las mentalidades y la antropología histórica, ¿qué es sino enfocar el pasado desde el punto de vista del actor, desde el interior? La cuestión no es sólo descubrir nuevos territorios y fuentes sino también revisar, desde el ángulo subjetivo, los viejos territorios y fuentes de una historia que, recordemos, ha ganado su reconocimiento como ciencia a fuerza de tratar como objetos los hechos y las huellas del pasado. El reto ahora no es otro que tratar científicamente la acción y la visión del sujeto de la historia.

Las fuentes narrativas tradicionales de la historia política no están siendo demasiado utilizadas por los historiadores de las mentalidades, quizás porque el acontecimiento histórico como tal, la corta duración, no es todavía materia habitual de trabajo para indagar la mentalidad. ${ }^{33}$ I as fuen. tes notariales y judiciales, explotadas principalmente por la historia demográfica, económica y social, empiezan a ser mayormente empleadas por el historiador de las mentalidades, especialmente los procesos ${ }^{34} \mathrm{y}$ los testamentos. 35

Para entender la subjetividad pasada, el historiador general precisa también echar mano de las fuentes propias de la historia cultural, mucho menos útiles para el estudio que los hechos políticos y socioeconómicos. Nos estamos refiriendo a la historia de la literatura, del arte, de la filosofia, de la religión, de la educación y de la ciencia. ${ }^{36}$ Éstas son subdisciplinas que han nacido del desarrollo diacrónico de áreas del conocimiento cultural que buscan de este modo el

33 Un intento en este sentido es la obra de Duby, Domingo, 1988.

34 Ginzburg, Queso, 1982; Le Roy Ladurie, Montaillou, 1981; Davis, Regreso, 1984; desde un punto de vista crítico véase Burke, Cultura, 1991 , pp. 126 y ss.

35 Tipo de documentos utilizados sobre todo para indagar acerca de la religiosidad y la idea de la muerte.

36 En épocas pretéritas la historia de la ciencia era inseparable de la historia de las mentalidades, verbigracia, Vicquers, Mentalidades, 1990. 
origen y la evolución temporal de su objeto.

La convergencia de temas, fuentes y métodos enriquece tanto la historia general como dichas especialidades históricas. ${ }^{37}$ El redescubrimiento de las fuentes de la cultura erudita por parte del historiador general tiene lugar al mismo tiempo que se revalorizan objetos y fuentes culturales antes considerados menores (prensa, fotogralia, ${ }^{38}$ literatura y arte populares, entre otros), o simplemente no considerados fuentes históricas, como es el caso de la cultura oral o de los documentos personales. Fuentes inexploradas que dan lugar incluso a nuevas subdisciplinas, como la historia oral. ${ }^{39}$

La ampliación del territorio del historiador hacia lo mental en general, y lo imaginario en particular, conduce por consiguiente a un nuevo aprovechamiento heurístico de la obra literaria, doctrinal o artística; por otro lado esta irrupción del historiador general -formado como historiador social por lo regular - en el campo de la historia cultural aporta a los historiadores de estas subdisciplinas -reafirmando en ocasiones tradiciones anteriores- los materiales necesarios para el enfoque sociológico y psicológico y también la preocupación por el sujeto colectivo, anónimo, popular.

37 Por ejemplo, la incorporación del enfoque sociológico a la historia cultural tradicional, dando paso a la nueva historia sociocultural; la aplicación de la semántica y de la semiótica a la historia para el estudio de las palabras, etcétera.

38 Freund, Fotografla, 1976; Riego, "Fotografia", 1990.

39 Joutard, Voces, 1985; Thompson, Voz, 1988.
La perspectiva que se ofrece al historiador de las mentalidades que investigue las fuentes clásicas de tipo literario, iconográfico ${ }^{40}$ y doctrinal es inmensa, aunque se va a encontrar con que muchos temas nuevos para la historia general son antiguos para los historiadores de la literatura o del arte, existiendo ya una bibliografia, a menudo extensa, al respecto. Tal vez la historia de la religión sea la rama historiográfica que $-a$ partir de la renovación que supuso la antropología histórica ${ }^{41}$ y la historia de las mentalidades ${ }^{42}$ - haya logrado hasta ahora la mejor síntesis de historia general/historia. 43

Si para el historiador de las mentalidades todas las fuentes son en principio válidas, y aun la novedad de su objeto pone de relieve nuevas fuen. tes, no ocurre lo mismo con el método y las técnicas que se aplican: para estudiar la subjetividad es necesaria por supuesto una metodología específica que no llega con el modus operandi general de los historiadores. Lo sorprendente sería lo contrario, iacaso la historia social o la historia económica

40 Añadamos las nuevas fuentes audiovisua. les (cine, radio, discos, Tv, video, computadora) que convierten en un privilegiado al investigador de las mentalidades de la historia inmediata.

¿l Eliade, Tratado, 1981; Thomas, Religion, 1971.

42 Bloch, Rois, 1962; Febvre, Problème, 1968.

43 La historia de la religiosidad medieval ha dado lugar, por ejemplo, a una importante línea de investigación: Manselli, Religión, 1975; Schmitt, Herejía, 1984; Delumeau, Che. min, 1981; Le Goff, Nacimiento, 1985; Dupront, Sacré, 1987; Geremek, Piedad, 1989; Delumeau, Pardon, 1990. 
o la historia del arte no tienen su propio método de trabajo? Hay herramientas y enfoques metodologicos de la historia, en cuanto ciencia social, que conciernen a todas sus ramas, pero es la singularidad del objeto de investigación, en este caso la mentalidad, lo que obliga a descubrir y a producir medios singulares para plantear preguntas sobre la base de las fuentes y de verificar las respuestas que se van obteniendo. Y para sacar conclusiones mentales de un texto, un hecho, un testimonio o una imagen (o de la ausencia de ellos) es menester buscar inspiración en las ciencias sociales más experimentadas en los temas de la psique, esto es la psicología y la antropología. ${ }^{44}$ De la misma forma que la historia ha colaborado con la geografía, la sociología y la economía para construir el método de la historia social y económica, asimismo ha de cooperar con la antropología y la psicología para crear los instrumentos que permitan el acceso a la subjetividad humana. La historia de las mentalidades es interdisciplinaria o no es. ${ }^{45}$ Cierto que el factor tiempo prohibe tratar los hechos históricos, materiales

44 La formidable demora de la historia en abordar el estudio de lo mental no es comparable a las demás ciencias sociales que ambicionan aprehender totalidades; hablamos de la antropología, pero también de la sociología; $\sin$ la convergencia con la sociología no hubieran nacido la psicología social y la antropología social, que no por azar es como se conoce en la actualidad a la antropología histórica en los países anglosajones.

45 El primer objetivo de la interdisciplinariedad se deduce de lo dicho anteriormente: la convergencia entre historia general y las historias especializadas. o mentales como si fuesen actuales. ${ }^{46}$ La diferencia de objeto lo indica el intercambio más que el trasplante entre la historia y sus disciplinas vecinas. ${ }^{47}$ Siendo conscientes de la importancia capital de sus contribuciones genéticas y diacrónicas, los historiadores debemos aprender de las ciencias sociales que van por delante en la tarea de dar un tratamiento científico a la mentalidad, con el mismo entusiasmo y los buenos resultados con que algunos estudiaron los tratados de geografia, sociología o economía en los tiempos en que arrancaba la nueva historia, sin que ello tenga naturalmente por qué implicar una nociva dependencia de dichas disciplinas.

\section{UN PRODUCTO FRANCÉS}

La historiografia de diversos paises ha recorrido con distintos pero convergentes resultados el camino de lo objetivo a lo subjetivo. La experiencia renovadora más influyente entre nosotros, positiva y negativamente, es sin duda un producto francés: la historia de las mentalidades. La prueba es que en España se conoce por ese nombre en el presente la historia de la subjetividad humana en general, las nuevas temáticas de la antropología, y la cultura y la psicología aplicadas a la historia. Nos parece teóricamente mucho más claro denominar bisto-

46 En rigor todos los hechos que analizamos son, de inmediato, hechos pasados; lo que pasa es que la antigüedad es un dato cualitativo, y la historia está justarnente especializada en investigar científicamente la cualidad de lo antiguo.

47 Stengers, Sctence, 1987. 
ria subjetiva a una constelación de nuevas historias que tienen por objeto al sujeto, distinguiendo en su interior (pues ni por su origen, mate. rias o métodos se trata de campos verdaderamente homólogos) cuando menos a la historia de las mentalidades en su sentido más estricto, la antropología histórica, la historia sociocultural y finalmente la psicohistoria. La cuestión es que, hoy por hoy, estas cuatro denominaciones se utilizan a menudo sinónimamente, tendiendo cada una a englobar el espacio de las otras. En Francia se entiende a la historia de las mentalidades como la gran abarcadora de temas superestructurales; el término más extendido en la historiografia mundial es, por lo demás, el de antropología histórica o social. Valiéndose de la cultura en su acepción más amplia, historia cultural es un término aplicado en ocasiones para designar todo lo subjetivo; en Estados Unidos se identifica con frecuencia la historia de las mentalidades con la psicohistoria. El peso innegable de las tradiciones nacionales obstaculiza, junto con otras causas, la clarificación y establecimiento de relaciones de comunidad y de parentesco entre estas líneas paralelas -que se interpenetran- de la investigación subjetiva. Con todo, la historia francesa de las mentalidades ocupa por méritos propios un papél central en la génesis y en la realidad floreciente de una historia subjetiva que impulsa una investigación de vanguardia en distintos países e historiografias, incluyendo a las historiografias marxistas. ${ }^{48}$

18 La investigación del sujeto historico esta, desde hace un tiempo, contribuyendo mucho a
En su afán por combatir la historia tradicional, descriptiva de acontecimientos, y por construir una nueva historia explicativa, social y total, Marc Bloch y Lucien Febvre, fundadores en 1929 de la revista Annales, avanzaron dos líneas de investigación, de entrada interconectadas pero que más tarde se bifurcaron: la historia socioeconómica y la historia de las mentalidades. 49 Ia primera fue haciéndose predominante en Francia a partir de la segunda guerra mundial, especialmente en los años sesenta, siendo desplazada de su posición hegemónica por la historia de las mentalidades a lo largo de la década siguiente. ${ }^{50}$ De modo que en los años ochenta asistimos al clímax de una historia de las mentalidades que se amplía y difunde entre las disciplinas más próximas, perdiendo la noción de mentalidad en definición precisa lo que gana en extensión, en beneficio de una emergente antropología histórica, merced al empuje de la antropología en el conjunto de las ciencias sociales y al peso de las historiografias anglosajonas. E1

renovar una historiografia marxista volcada en una historia objetiva de la base material de la sociedad, necesaria, en su momento, para construir una historia científica pero que resulta insuficiente, no solo para la historia como disciplina global, sino también para un marxismo que no se reduzca a un economicismo.

4 Nos hemos referido con mayor amplitud a todo esto en Barros, "Historia", 1989.

50 En 1979, en el Institut de Recbercbes Mar$x$ tstes, Michel Vovelle testificaba que "la historia de las mentalidades es hoy una causa ganada [...] en Francia al menos, las mentalidades, en tanto que locomotora de la historia, parecen haber destronado la historia económica, y aun la historia social", Vovelle, "Inconsciente", 1985, p. 86. 
reciclaje de la historia de las mentalidades -que comporta una suerte de segundo impulso-como antropología histórica, durante la década pasada, ha favorecido la homologación francesa con pujantes historiografias, en primer lugar las anglosajonas, resistentes al hegemonismo francés, actualmente demodé en el mundo intelectual. ${ }^{51}$ Las reservas, cuando no los prejuicios, hacia lo francés no dejan de constituir una moda más.

El "error" francés, cuya rectificación hay que contemplar en el marco del tournant critique en marcha de la historiografia del país vecino, ha sido manifiestamente separar-siguiendo el péndulo- la historia social -y la psicología social- de la historia de las mentalidades; ello ha posibilitado colaboraciones realmente innovadoras en relación con la antropología, el arte, la literatura y otras disciplinas de lo subjetivo, pero también ha alejado a la nouvelle bistoire de la historia total... y de otras historiografias, entre ellas la española.

\section{EL. RETRASO ESPAÑOL}

Que la puesta al día de la historiografia española, durante los años sesenta y setenta, haya tenido lugar

51 No se puede olvidar que en el mundo de las ideas, la cultura y la comunicación, hemos asistido en los últimos ańos a la pérdida por parte de Francia y de París de un papel protagonico (que tiene, sin duda, su epicentro, en 1968) en beneficio de Estados Unidos y de la cultura anglosajona, lo que beneficia así mismo al sector más innovador y progresista de la historiografia norteamericana e inglesa. bajo un régimen político de dictadura, con todas sus implicaciones ideológicas, académicas y de obstáculos a la movilidad, ha retrasado -de manera acumulativa- la conexión de los historiadores españoles con las investigaciones de vanguardia en sus disciplinas, provocando un ritmo historiográfico peculiar. Las innovaciones acaban llegando a España, pero de manera parcial y con una demora evidente (al menos de una década). Así, la historia socioeconómica se impone entre nosotros sobre todo en los años setenta renovando decisivamente la vieja historia, 52 bajo la influencia directa de la escuela de Annales, cuando ya en Francia ${ }^{53}$ ascendia a un primer plano una historia de las mentalidades que tendía a distanciarse de la historia social de las mentalidades de los años sesenta (pensemoṣ en las in. vestigaciones y las reflexiones en esos años de Mandrou, Duby y Le Goff) ${ }^{54}$ Así es como la nueva historia socioeconómica española se consolida contra la historia de las mentalidades, al margen de las demás corrientes que en la historia y ciencias sociales mantenían o incluso concentraban su in-

52 Por fin se abandonaba la historia evénementielle que había predominado desde el final de la guerra civil, Valdeon, "Quince", 1991.

53 Y no sólo en Francia, en 1971 Thomas publico Religion, y en 1963 se edito la obra de Thompson, Formación; ambas representativas del diálogo historia-antropología que, paralelamente, los historiadores ingleses habían iniciado para responder a preguntas bastante parecidas a las que dieron origen a la historia de las mentalidades en Francia.

51 Mandrou, Introduction, 1961, "Histoire", 1968; Duby, "Histoire", 1961; Le Goff, Civilisation, 1964. 
terés en el sujeto-hombre y en la superestructura de la sociedad. ${ }^{55}$ iExistía otra alternativa? Teóricamente sí, la im. periosa necesidad de investigar la base material de la sociedad no tenía por qué cerrar el acceso a la dimensión subjetiva y cultural de la realidad, cuya investigación -convenzámonosno tiene por qué ser menos científica que la de la economía. En la práctica no ha sido asi, tal vez porque la tarea ingente que suponía la superación de la historia tradicional en las condiciones españolas no permitía una diversificación del esfuerzo innovador. Máxime cuando ello comportaría trabajar en direcciones tan disímiles $y$ difíciles de compatibilizar, incluyo hoy, como lo material y lo mental.

Historiadores españoles, con más facilidades para el contacto con el exterior, ${ }^{56}$ que entonces pasaba ante todo por Francia, ensayaron el desarrollo de una historia social que fuese a la vez historia de las mentalidades; pero no fueron seguidos, ni siquiera en cuanto a la aceptación de la historia de las mentalidades como un campo útil y necesario para la investigación global del pasado. Reyna Pastor, en 1966, publicó en francés un trabajo que siete años después alcanzó cierta difusión en español, Diego Gelmírez: una mentalidad al dia.,57 que quería

55 Por ejemplo, la historia social inglesa (de cuya inclinación antropológica ya hemos hablado), y la Escuela de Francfort.

${ }^{56}$ Los dos autores que vamos a citar no vivían en ese momento en Espana.

57 Editado junto con otros artículos de historia social y económica, Pastor, "Diego", 1973, pp. 104-131; en este artículo se aborda también desde posiciones nuevas el género ser "un ensayo de análisis interdisciplinario que permitirá el conocimiento de ciertas 'actitudes mentales'". 58 En el mismo año, 1973, Manuel Tuñón de Lara -siguiendo a Labrousse, Mandrou y Duby-, incluye en su Metodologia de la bistoria social de España un capítulo que dice: "De la historia social a la historia de las mentalidades sociales: posibles fuentes y métodos de conocimiento." 59 Sin embargo, dos años después, salvo Antonio Elorza, ${ }^{60}$ ninguno de los historiadores que escriben sobre metodología en el Boletín Informattvo de la Fundación Juan March promueven la historia de las mentalidades como ca. mino adecuado para la nueva historia española, a pesar de las aportaciones más novedosas a Annales de lo que después se editó como Once ensayos sobre la bistoria (1976), sin duda la contribución colectiva más sugestiva en aquellos tiempos sobre renovación metodológica hecha en España por historiadores. ${ }^{61}$

biográfico, hecho bastante insólito y audaz en la historiografía marxista de los sesenta.

58 Ibid., p. 108.

59 Recientemente Tuñón de Lara. ha citado como concreciones posteriores de esta línea de investigación los trabajos publicados en Historia 16: (1977) de Carmen García Gaite y María Cruz Seoane sobre los esfuerzos del franquismo por buscar una tradición, y de Luis Alonso Tejeda sobre la represión sexual bajo el franquismo, Tuñón de Eara, "Historia", 1991, p. 166.

60 Que comienza su artículo sobre las ideologías políticas y su historia citando la Metodologla de Tuñón de Lara, Once, 1976, pp. 71-77.

61 Sobre la situación posterior, valdeón escribe: "La historiografía española de los últimos quince años refleja, desde otro punto de vista, una notable pobreza: tebrica y meto- 
El problema de la recepción de $A \boldsymbol{n}$ nales en la historiografia española de los setenta es su parcialidad. Faltó la preocupación por la historia total, clave para entender no sólo Annales sino también un materialismo histórico evolucionado, que contemple y entrelace todos los niveles de la realidad, integrando el factor subjetivo, humano, en la historia.

En 1970 una editorial publicaba en Barcelona Combats pour l'bistoire de Lucien Febvre, pero significativamente faltaban dos artículos, que aún siguen inéditos en español, presentes en la versión francesa (1953): "Une vue d'ensemble. Histoire et psychologie", y "La sensibilité et l'histoire. Comment reconstituer la vie affective d'autrefois?" Una explicación podría ser, y así se dice, que Febvre tuvo una acogida menos favorable en nuestro país que el otro, más fundamen. tal y más próximo al materialismo histórico, fundador de la nueva historia francesa, Marc Bloch. Pero el caso es que La société féodale (1939) se publica en español... hasta $1986 ;{ }^{*}$ de haberse editado 10 o 15 años antes no hubiera dejado de inspirar la renovada historiografía española esa interrelación de "condiciones de vida y atmósfera mental", que Bloch ensaya en esa síntesis maestra de una estruc.

dologica. Sin duda en estos campos la contribución española nunca ha sido muy destacada", "Quince", 1991, p. 163. Sobra decir que esta despreocupación de los historiadores con la teoría y la metodología está también en la base de las dificultades para la asimilación y la producción de las innovaciones.

" la edición de uteah es de 1958. Y otra, de la misma editorial, con copy right de 1978. [N. del E.] tura social. En este contexto de lectura incompleta de las enseñanzas de Annales por parte de nuestra mejor historiografía (marxista y no marxista), se comprende mejor que la primera gran obra de Bloch, estudio de una creencia colectiva, Les rois thaumaturges (1924), se haya traducido al caste. llano hasta hace muy poco, ${ }^{62}$ y que, en otro orden de cosas, la descalificación global de la historia de las mentalidades al estilo francés ${ }^{63}$ haya supuesto la minusvaloración e incluso el desconocimiento o marginación de una línea de historia social de las menta. lidades que, originada en Bloch y Lefebvre en el periodo de entreguerras, fue retomada por Robert Mandrou, Georges Duby, Jacques Le Golf en los años sesenta, y continuada posteriormente por Michel Vovelle, Maurice Agulhon y muchos otros. La edición en 1985 (Barcelona) de Ideologies et mentalités (1982) de Michel Vovelle, conjunto de ensayos de valor me. todológico inestimable -sobre todo para el historiador próximo al marxismo-, y otras aportaciones quizá menos divulgadas, ${ }^{64}$ preparan las condiciones para lo que Julio Valdeon ha llamado "la irrupción de la denominada bistoria de las mentalidades", 65 cuya

62 Fondo de Cultura Econónica ha publicado esta obra de Bloch (1988). Sobre la génesis y el valor de esta investigación, véase el prólogo de Jacques le Goff a la tercera edición en frances (1983) y Dosee, Historia, 1989 , pp. 89-92.

63 Cajón de sastre donde entran justos y pecadores, críticas que el tiempo ha demostrado ser correctas y excesos hipercríticos que rayan en el simple prejuicio.

64 Como la ponencia de Benassar, presentada en las III Conversaciones Internacionales de Historia, "Mentalidades", 1985.

65 Valdeón, "Quince", 1991, p. 162. 
presencia en conferencias, seminarios, lecturas de tesinas y tesis, y en algunas publicaciones, empieza a notarse seriamente de 1988 en adelante. ${ }^{66} \mathrm{~A}$ quince años del primer planteamiento animador de Tuñón de Lara, la historia de las mentalidades está dejando de ir a contracorriente. Este retraso, consecuencia del hábito anterior en la recepción de la historia socioe. conómica, ${ }^{67}$ tiene sus incovenientes pero también sus ventajas.

\section{INCONVENIENTES Y VENTAIAS DE UN APOGEO TARDÍO}

Inconvenientes del retardo de la historiografia española en investigar la historia desde la subjetividad. En primer lugar, cierta desconexión -y deficiente asimilación-de la última historiografia extranjera, no sólo la francesa, entrada acostumbrada a la innovación historiográfica en España. Lo que se ha rechazado como producto francés, como historia de las mentalidades, ha entrado en nuestro país como antropología histórica inglesa, como historia cultural americana o incluso como microhistoria italiana, si bien con su propio retraso. ${ }^{68}$ Caso notorio es el de

66 Se podra ver por ejemplo ordenando cronologicamente [estadísticas] historicas sobre la muerte en nuestro país.

67 Un nuevo campo de investigación se impone en la medida que el anterior aparece suficientemente trabajado; esta tendencia, y la búsqueda de la novedad -que produce la innovación, consustancial con la ciencia, pero también con la moda-, produce el sabido efecto pendular que hay que contrarrestar con energía y fundamentación teorica.

68 Olabarri anotaba justamente, en 1984, que la antropología inglesa, por desgracia, ha in-
The great cat massacre (1984) del historiador norteamericano Robert Darnton, colección de ensayos sobre actitudes y creencias en la Francia del siglo XvII, ${ }^{69}$ que -habiendo alcanzado un gran éxito de público en Estados Unidos y en Francia, y desatado además la polémica entre historiadores de varios países- pasó bastante inadvertido en España, pese a haber sido traducido y editado en México en 1987: consecuencia de la desconexión internacional y, consiguientemente, de una difícil homologación con algunas investigaciones ajenas a los temas y métodos habituales en nuestro país.

Es imposible una auténtica tradición historiográfica sin estar al día con

fluido poco en España, Historiografia, 1985, p. 125; como muestras, el hecho de no haberse traducido el libro de Thomas, Religion, 1971 (autor de quien se acaba de publicar un importante ensayo de 1963, "Antropología", 1989) y la tardía (Madrid, 1991) traducción del libro de Burke, Popular culture in early modern Eunope, 1978; sin embargo, los libros de Ginzburg, Queso (1976), 1981 -y de Levy, Herencia (1985), 1991- han tenido mejor fortuna; el carácter eminentemente social de la microhistoria italiana garantiza tal vez una mayor comprension y acogida en nuestra historiografia; prueba de ello es el Coloquio Internacional de Historia Local de Valencia, celebrado en 1988 (L'esapt viscuit, Valencia, 1989).

69 El propio Darnton ubica metodológica. mente su libro: "La investigación recorre el territorio inexplorado que en Francia se denomino l'bistoire des mentalités. Este campo aún no tiene nombre en inglés, pero sencillamente podría llamarse historia cultural, porque trata nuestra civilización de la misma manera como los antropólogos estudian las culturas extranjeras. Es historia con espíritu etnográfico", Darnton, Masacre, 1987, p. 11; la cita ilustra lo que más arriba dijimos acerca de la sinonimia entre historia de las mentalidades, historia cultural y antropología histórica. 
espíritu abierto -es decir, científicoa los avances, influencias y discusiones que tienen lugar en otras historiografías. ${ }^{70}$ Todo discurso sobre la interdisciplinariedad carece de sentido si, simultáneamente, no se mantienen, refuerzan y diversifican las relaciones internacionales con espíritu abiertamente crítico pero también autocrítico. Ciertamente, "en España no ha surgiclo ninguna corriente historiográfica original en lo que va del siglo". ${ }^{71}$ ¿Por qué? Además de la consabida indigencia teórica de nuestra historiografía, carecemos de la capa. cidad para sostener una relación suficiente, creadora y constructiva con la producción exterior. ${ }^{72}$

La historia que estamos bautizando como subjetiva, bajo sus distintas formas, es descle hace un tiempo la locomotora de la historia para muchos historiadores, y reúne hoy, en nuestra opinión, tendençias seriamente innovacoras de la historiografia mundial, ${ }^{73}$

70 Es preciso reconocer el papel activo que en este sentido están jugando las revistas de historia de Cataluña y el País Valenciano: LAvenc, Manuscrits, Debats, Historia Social y Revista d'Historia Medieval.

71 Julia, Historia, 1989 , p. vII; lo que no excluye valorar en sus justos términos el que se pusieran los cimientos de una historiografia que pudiera reclamarse del siglo $\mathbf{x x}$.

72 "Somos muy rápidos, muy a menudo esquemáticos y no raramente ignorantes en la crítica de lo que otros hacen, y tendemos a superar, antes de practicarlas, corrientes que en otros países, otras comunidades académicas, han dado resultados apreciables. Pero esta crítica acerada se compadece mal con nuestra propia capacidad de arriesgar la marcha por nuevos caminos", Julia, Historia, 1989, p. vil.

73 Sería una torpeza tacharlas de simples modas, sin profundizar más; la propia historia francesa de las mentalidades tiene una historia demasiado prolongada para ser (des)calificada en las que se percibe a cada pais arribar al mismo sitio -o mejor dicho, a un sitio parecido- por vías originales pero paralelas. Hay que preguntarse si no es demasiado costoso y teóricamente inexplicable ${ }^{74}$ permanecer al margen de un frente historiográfico que está configurando la labor de los historiadores de un futuro próximo.

Una ventaja de la tardía incorporación de España a este conjunto de líneas de investigación ${ }^{75}$ es el amplio abanico de nuevas posibilidades recientemente surgidas, en comparación con las existentes hace 10015 años, tanto en el terreno de la historia de las mentalidades como en los de la antropología histórica, de la nueva his. toria cultural o de la psicología social histórica en ciernes. ${ }^{76}$ Ahora bien, en cuanto a temas de investigación subje.

de episodio efímero, se trata realmente de movimientos profundos de la historiografia, de la mentalidad y de la sociedad finisecular, que además están de moda, como lo estuvo por causas parecidas la historia socioeconómica hace veinte años.

74 Las corrientes historiográficas se distinguen cada vez menos por los temas que investigan: así tenemos que la historia socioeconómica hace mucho que es una disciplina compartida por historiadores de todas las concepciones, $y$ los historiadores marxiscas han jugado un papel capital en el despegue de la historia francesa de las mentalidades y de la antropología historica inglesa.

75 Emparentadas con el retorno de géneros tradicionales -enfocados en el mejor de los casos con una metodología renovada-como la historia biográfica, narrativa, política de acontecimientos, por un lado, y con la emergencia de nuevos sujetos históricos como las mujeres, el niño, la vejez, por otro; vertientes todas ellas de la inclinación general a una historia subjetiva, que aquí estamos abordando en su sentido más estricto, esto es: psicológico y cultural.

76 Gergen y Gergen, Historical, 1984. 
tiva, la primera tarea es no confundir unos con otros. ${ }^{77}$ Unos son específcos de la antropología histórica: familia, matrimonio, sexualidad, vida cotidiana o privada, fiesta, cuerpo, gestos, alimentación, enfermedad, ritual, mito, leyenda, tradición oral, brujería, cultura popular. Otros lo son de la historia cultural: lectura, alfabetización, educación, filosofia, arte, literatura, ciencia.

Como quiera, hay una mayor cercanía a nuestra tradición historiográfica de los temas sociopsicológicos de la historia de las mentalidades: desde los modelos de comportamiento hasta las representaciones sociales, pasando por las prácticas, las actitudes, los valores y las creencias colectivas, nociones que aplicadas a las estructuras mentales y a los procesos de cambio de mentalidades están dando pie a productivas líneas de investigación. El tema más estudiado en España de esta nueva historia pertenece más bien a este tercer apartado, la actitud ante la muerte, que ya había actuado como tema central en la década anterior en Francia, en los comienzos de la historia de las mentalidades, ligando el estudio reposado de la larga duración, en ocasiones fuera de un contexto social y temporal definidos.

La muerte como tema historiográfico, lanzado en el año 1941 por Lucien Febvre en Annales, en plena segunda guerra mundial, cuando la revista trataba de sobrevivir bajo el nuevo régi-

77 De hecho están entremezclados; parte de ellos son comunes a varias áreas de conocimiento, y es hasta conveniente yuxtaponer enfoques distintos, pero la realidad es que casi todos los temas de la subjetividad han sido desarrolla. dos por una disciplina más que por otra. men -sin Bloch, que pasó durante la ocupación a la clandestinidad-, es retomado en 1948 por un demógrafo, Philippe Ariès, en Histoire des populations françatses et de leurs attitudes devant la vie depuis le Xvime siècle, y en 1952 por Alberto Tenenti, a partir de las fuentes iconográficas, en La vie et la mort á travers l'art du XVe siècle. Philippe Ariès estudió en 1977 monográficamente el tema en L'bonme devant la mort, cuatro años después de que Michel Vovelle subtitulara, en 1973, Les attitudes devant la mort d'apres las clauses des testaments, su libro sobre la piedad barroca y descristianización en Provence en el siglo Xvil. ${ }^{78}$ Pierre Chaunu y su equipo, a su vez, se unen al carro al publicar en 1978 La mort á Paris, XVIe, XVIIe et XVIIIe siècle.

Un rasgo común de estas investigaciones de los años setenta es el abandono del tema de la vida por el tema de la muerte, cuando los dos estaban presentes en los trabajos pioneros de posguerra de Ariès y Tenenti. Preferencia que refleja el distanciamiento de la historia social y económica por parte de la historia de las mentalidades conforme la va reemplazando. La muerte como objeto de indagación histórica participa ciertamente de una ambigüedad productiva que ha auxiliado a la historia de las mentalidades en su ascensión en Francia, si bien hay que decir que en nuestro pais alienta el enfoque de la "historia de la muerte como una variable de la explicación social", como una historia "de la vida social, desde el punto de vista en que

78 Michel Vovelle publica más adelante una obra de conjunto, Mort, 1982. 


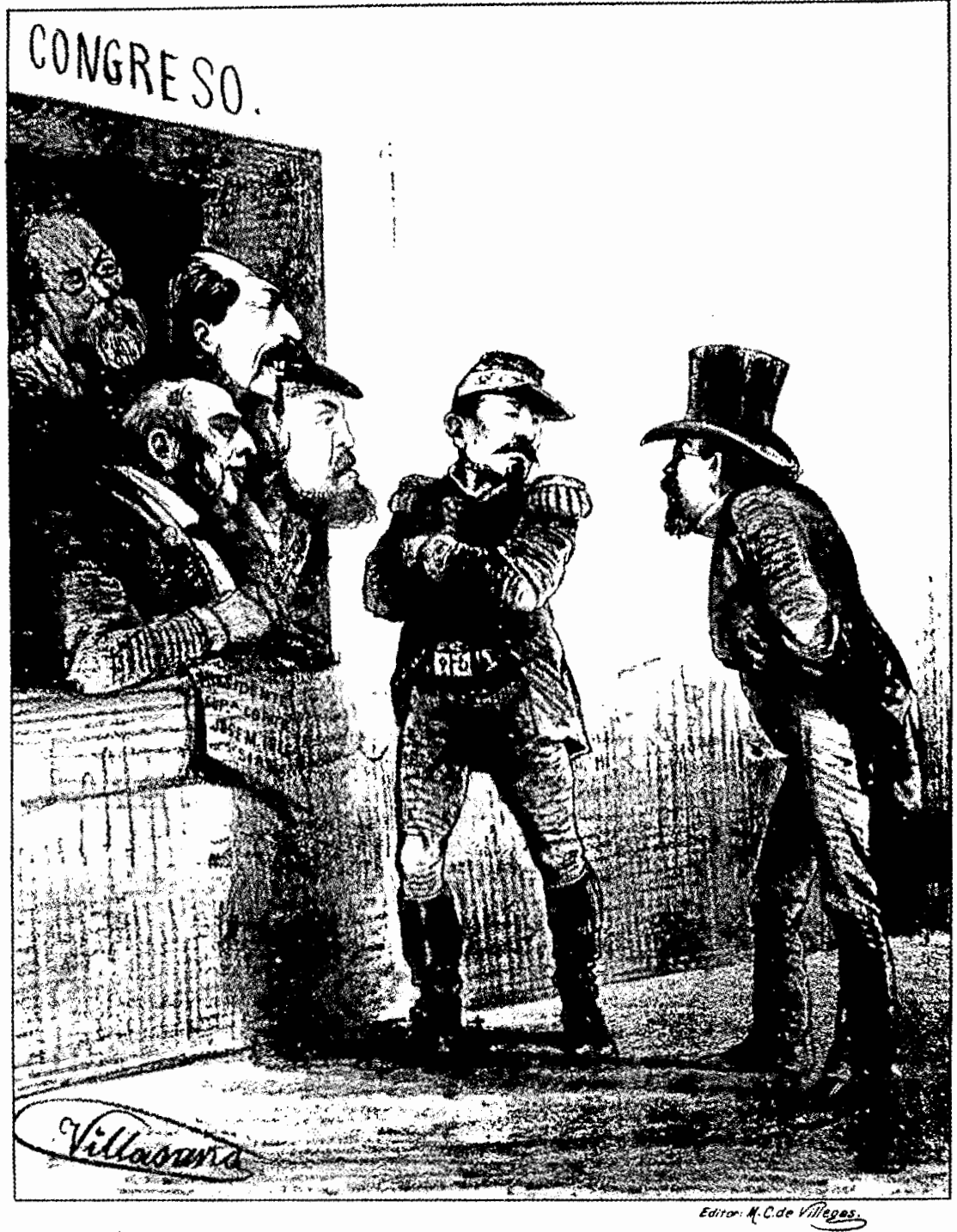

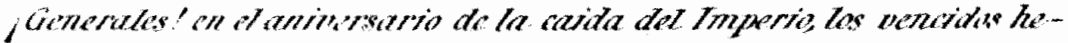

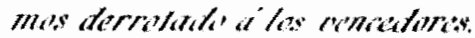


ésta es condicionada, explicada por la idea de la muerte". ${ }^{79}$

El estudio de las actitudes hacia la muerte, de los modernistas a los medievalistas, ${ }^{80}$ circula en Francia dejando paso a comienzos de los años ochenta a otros temas: comienza su penetración en España (con la subsiguiente década de retraso) ${ }^{81}$ como punta de lanza de la historia francesa de las mentalidades en la investigación de la edad moderna, ${ }^{82}$ de la edad media ${ }^{83} \mathrm{y}$, últimamente, de la edad contemporánea. ${ }^{84}$

El balance historiográfico sobre estos años de historia de la muerte en España no puede ser más que positivo, pese a que todavía no haya dado todos sus frutos. Además de su función introductora de la historia de las mentalidades en la década pasada, la indagación de las actitudes y representaciones de la muerte ha conseguido ya una colaboración interdisciplinaria con historiadores del arte, la literatura y la re190.

79 Portela y Pallares, "Muerte", 1985, pp. 189,

${ }^{80}$ En 1975 se celebró el coloquio La mort au Moyen Age (Istra, 1977).

${ }^{81}$ Hay un esfuerzo de los hispanistas franceses desde los años setenta por investigar la historia de las mentalidades españolas, que en lo inmediato -como todos los demás intentos introductorios del nuevo campo de investigacionno cuaja: algunos ejemplos: Bennassar, Homme, 1975; Rucquoi, "Corps", 1981.

82 Barreiro, "Sentido", 1975; Rey Castelao, "Clero", 1981; García Cárcel, "Muerte", 1984; López, Oviedo, 1985; Moya y Armengol, "Consciencia", 1985; Lorenzo Pinar, Actitudes, 1989; Martínez Gil, "Muerte", 1990.

83 Portela y Pallares, "Muerte", 1985; Arranz, "Reflexion", 1986; Mitre Fernández, Vencida, 1988; Portela y Núñez, Idea, 1988; Martín y Bazan, "Renacentista", 1988; Guiance, Medievales, 1989.

84 Vaquero Iglesias, "Muerte", 1989. ligión, evitando asimismo en general ese "doble riesgo de la atemporalidad y la superficialidad". 85

Pero, con todo, se trata de un resultado limitado: la historia de la muerte no ha dejado de ser un tema secundario, aislado de nuestra historiografia reciente. Ahora, el auge de la historia de las mentalidades desde finales de los años ochenta ha traído consigo una benéfica multiplicación temática y, en algunos casos, la disminución del desfase temporal con respecto a la historiografia foránea. Otros objetos de investigación mental y psicológica que ganan espacio historiográfico en nuestro país: imagen del rey; justicia, criminalidad y violencia; conflictos y revueltas; caballeros y clérigos; tiempo; espacio. A los que hay que sumar los propios de la antropología histórica: familia, cultura popular, tradición oral, enfermedad, fiesta, alimentación, sexualidad, infancia, vida cotidiana $y$ religiosidad popular. Sin olvidar la renovación metodológica de la historia cultural y sus temas. Todo indica que en la década de los noventa vamos a vivir la generalización y -es de desearla consolidación de estas nuevas historias de la subjetividad.

Otro síntoma, indirecto pero significativo, de este apogeo de la historia de las mentalidades en España es el (re)descubrimiento por parte de la psicología y de la antropología de la noción de mentalidad en cuanto objeto de estudio, lo que crea precondiciones para un diálogo inexcusable de la historia con dichas disciplinas para hacer avanzar una temática de investigación que, no lo olvidemos, tiene

85 Portera y Pallares, "Muerte", 1985, p. 190. 
como pilar básico de su metodología la interdisciplinariedad.

La verdad es que la apertura de estas ciencias de la subjetividad hacia la historia no halla fácil correspondencia entre historiadores hasta el momento alejados, salvo excepciones, de las materias de investigación de la antropología y más aún de la psicología, llegando al extremo de negar en la práctica estatus científico a la investigación de la psique y de otras actividades humanas (sentimientos, sexo, etc.). ¿Cómo se puede entender que estos temas sean importantes para el conocimiento científico de las sociedacles actuales o "primitivas", y no lo sean para las sociedades históricas? Otra cuestión es cómo compatibilizar y sintetizar los nuevos con los viejos enfoques. Para muchos está por verse la productividad de los nuevos temas y métodos, dubitación que pierde su le. gitimidad y efectividad cuando se encasilla a priori, globalmente, tal o cual tema de la antropología o de la psicología en el campo de una historia frívola, infradivulgativa.

Sin la alianza interdisciplinaria de la historia con la psicología y la antropología no es viable una renovación historiográfica que tenga por base -aunque no la única- a la historia de las mentalidades; no es otra la experiencia de las historiografias más avanzadas. Veamos los pronunciamientos españoles a que hicimos referencia. José Luis Pinillos enlaza la historia de las mentalidades de Annales y la psicohistoria norteamericana con la preocupación de la filosofia alemana por la psicología de los pueblos (Völkerpsychologie), y anima a los psicólogos de hoy -cognitivos- a considerar la historicidad de las mentalidades colectivas que "poseen un espesor, una profundidad histórica y no son puramente actuales" y valora autocríticamente que "la hegemonía de un modelo epistemológico inspirado en la ciencia natural del siglo pasado $[\ldots]$ ha dificultado quizá la debida incorporación a la psicología científica de un ingrediente del comportamiento humano tan importante como es de hecho la mentalidad dominante en un momento dado". Termina por plantear la investigación de la mentalidad global como vía de renovación para la psicología española: "Honestamente creemos que la psicología debe esforzarse por abordar la cuestión, actualizando sus planteamientos. El momento es propicio para ello." ${ }^{66}$ Por su lado, Julio Caro Baroja habla en el homenaje de la Universidad de Barcelona a Antonio Domínguez Ortiz sobre el estudio histórico de las llamadas mentalidades en una dirección bastante pa. recida a la del psicólogo José Luis Pinillos. Partiendo de la antropología y de su propia obra, ${ }^{87}$ llama la atención sobre el estudio de las mentalidades globales y esboza asismismo una cla. sificación según los ámbitos o los sujetos, tomando por mentalidad "la di. versidad de lo pensado en una misma lengua". 88

86 Pinillos, "Problema", 1989, p. 467.

87 Cita en concreto: Caro Baroja, Formas, 1978; precedente inexcusable para la historia de la religiosidad moderna, y para otros temas como la muerte (utilizando fuentes narrativas), la marginalidad (representación colectiva del pobre), etc.; una experiencia reciente de cooperación antropólogos-historiadores, Religio. sidad popular, 3 vols., Madrid, 1989.

88 Caro Baroja, Reflexiones, 1990, p. 72. 


\section{CONCLUSIÓN}

Las tentativas individuales de historiadores españoles de abrir paso, hace diez o veinte años, a la historia de las mentalidades fracasaron, desafortunadamente, a corto plazo. No pocos de ellos volvieron a la historia socioeconómica, cuya madurez y calidad es reconocida internacionalmente, o en el mejor de los casos buscaron la innovación en terrenos antropológicos de entrada menos conflictivos (cultura popular, familia, oralidad), quizás más alejados de la denostada histo. ria francesa de las mentalidades 0 más cercanos a la historia social inglesa o italiana, y por tanto a nuestra última tradición historiográfica. Ahora bien, ¿no está cambiando el viento de đirección? Vimos cómo la presente irrupción de las mentalidades supone un descubrimiento acelerado de nuevos territorios de la investigación: ia dónde nos puede llevar una eclosión más que previsible de todas estas novedades? Tanto puede valer para trivializar y fragmentar el oficio de historiador como para renovar la historia que se hace en España. Y hasta es factible que, en un inicio, sirva simultáneamente para ambas cosas.

La dispersión temática y metodológica de la historia es hoy por hoy un problema generalizado, en parte consecuencia del crecimiento y de la especialización, cuyo antidoto no consiste obviamente en retroceder a un discurso historiográfico monocorde, limitado en sus temas y encerrado sobre sí mismo, sino en conservar el vigente y necesario concepto de una historia total de la sociedad, alter- nando síntesis con análisis, pactando con las disciplinas vecinas sin por ello diluir el papel de la historia y sus métodos ni renunciar a su aportación clave en el conjunto de las ciencias sociales. Junto con el peligro evidente de eclecticismo ante la proliferación de temas y métodos, y la relativización de las teorías, urge también contemplar el riesgo inmovilista de colocar bajo sospecha los intentos de renovar nuestra historiografia, que no siempre van a ser acertados. El quid de la cuestión está en contrarrestar la tendencia pendular ocupando los nuevos territorios de la investigación pero sin renunciar a los viejos. La innovación que perdura es aquella que debe menos a la moda, porque se impone científicamente, esto es: conservando todo lo que es válido de los paradigmas anteriores; dicho metafóricamente: echando el agua sucia de la bañera pero dejando al niño dentro.

La gran ventaja del retraso español reside entonces en que nuestra historiografía está aprendiendo en cabeza ajena. La historia de las mentalidades resulta viable como factor de renovación en la medida en que aparezca vinculada a la historia social; esto es, siempre y cuando nos aproxime a la meta de una historia total, entendida como articulación compleja y no como simple adición de los diversos niveles de la realidad. Constituyendo la historia social la parte más sólida de nuestra reciente historiografia, el primer objetivo del historiador de las mentalidades es, pues, completar la investigación social anterior analizando su dimensión psicológica, cultural y antropológica, y planteando desde otro punto de vista nuevas pre- 
guntas y nuevas respuestas. La originalidad española de una línea de investigación sobre mentalidades colectivas está entonces, según nuestro criterio, en una historia social de las mentalidades, que no tiene por qué comportar el abandono de la indagación de cualquier aspecto de la actividad humana en el pasado que pueda contribuir, desde una primera instancia, directa o indirectamente, a explicar una historia que el hombre como sujeto indudablemente produce. Lo importante es no olvidar las condiciones objetivas, ante todo materiales, con las cuales establece una relación dialéctica (más fácil de enunciar que de encontrar en los hechos). Una historia social de las mentalidades que tienda a la historia total. Una historia social de las mentalidades que sabe que no es más ni menos que la parte subjetiva de la historia.

\section{BIBLIOGRAFÍA}

-Arranz, A., "La reflexión sobre la muerte en el medievo hispánico. ¿Continuidad o ruptura?", La España Medieval, vol. I, 1986.

-Baczko, B., Les imaginaires sociales: mémoires et espoirs collectifs, París, 1984.

-Barreiro, B., "El sentido religioso del hombre ante la muerte en el Antiguo Régimen. Un estudio sobre archivos parroquiales y testamentos notariales", I Jornadas de metodología aplicada de las ciencias históricas, vol. v, 1975.

-Barros, Carlos, "Historia de las mentalidades, historia social", en Problemas de renovación bistoriográfica: la bistoria de las mentalidades, Valladolid, 1989.

- , "Historia de las mentalidades", en La Historiografia de Occidente desde 1945, Pamplona, 1985. 1990.

-Berge, Yves-Marie, Le roi cacbe, París,

-Besançon, Alain (comp.), L'bistoire psycbanalytique. Une antbologie, 1974.

-Bínion, Rudolph, Introducción a la psicobistoria, México, 1986 (París, 1982).

-Bloch, Marc, Les rois thaumaturges, Estrasburgo, 1962 [Los reyes taumaturgos, Fondo de Cultura Económica, México, 1988].

-Boureau, Alain, Le simple corps du rot. Limpossible sacralité des souverains français, xve-xvile siècle, París, 1988.

-Burke, P., La cultura popular en la Europa moderna, Madrid, 1991 (1978).

-Caro Baroja, Julio, Las formas complejas de la vida religiosa, Akal Editores, Ma. drid, 1978.

viejos temas, Madrid, 1990.

-Castoriadis, Comelius, Linstitution imaginatre de la societé, París, 1975.

-Cerquigliani, B., "Linguistique et histoire", Dictionaire des sctences bistortques, París, 1986.

-Chesnais, Jean-Claude, Histoire de la violence, París, 1981.

-Chevalier, Jean-Claude, "La lengua, lingüística e historia", Hacer la Historta, vol. III, 1980.

-Chiffoleau, J., "La violence au quotidien, Avignon au XIVe au xvile siècle d'après les registres de la cour temporelle", Mélan ges de l'Ecole Française de Roma, vol. XcI, núm. 2, 1980.

-Darnton, Robert, La gran masacie de gatos y otros ensayos en la bistoria de la cultura francesa, Fondo de Cultura Económica, México, 1987.

-Davis, N. Z., El regreso de Martin Guerre, Barcelona, 1984.

-Delumeau, Jean, La peur en Occident (Xrv.XVII siècles), París, 1978 (Madrid, 1988). , Un chemin d'bistoire. Cbrétienté et christianisation, París, 1981.

, Rassurer et protéger. La sentiment de sécurite dans l'Occident d'autrefots, París, 1989. 
, Laveu et le pardon Les dif ficultes de la confession (13e-18e siecle), Pạtís, 1990.

-Dosse, Françoise, La bistoria en migajas, de los "Annales" a la meva bistovia, Edicions Alfons El Magnanim, Valencia, 1989.

-Duby G., "Histoire des mentalités", en L'bistoire et ses métbodes, París, 1961. , El domingo de Botvines: 24 de julio de 1214, Madrid, 1988.

-Dupront, Alphonse, "Sémantique historique et histoire", Cabiers de Lexicologie, núm. 15, 1969.

- "Language et histoire", $X I I$ Congrès International des Sciences Historiques, Moscú, 1970.

, Du sacré. Croisades et pele vinages. Images et langages, París, 1987.

-Duvignaud, Jean, la genèse des pas. sions dans la vie sociale, París, 1990.

-Eliade, Mircea, Tratado de bistoria de las religiones, Madrï, 1981.

Hlias, Norbert, El proceso de la civilización. Investigaciones sociogenéticas y psicogenúticas, Fondo de Cultura Económica, Madrid, 1987.

-Erlande Brandenburg, A., Le roi est mort. Étude sur les funerailles, les sepultures et les tombeaux des rois de France jusqu'a a la fin du xare siècle, Ginebra, 1975.

-Farge, A., La vie fragile. Violence, pouvoirs et solidaritès à Paris au Xvine siècles, Patis, 1986.

-Febvie, Lucjen, "Histoire des sentiments. La Terteur", Annales. Economies Sociérés Civilisations, París, 1951.

__ "La mort dans l'histoire", Annales. Economies Sociétes Civilisations, paris, 1952.

___ "La sensibilité et l'historie. Comment reconstituer la vie affective d'autiefois?", Combats pour l'bistoire, Librairic Armand Colin, París, 1953 (excluido de Combates por la bistoria, Ariel, Barcclona, 1970.) , "Pour l'historie d'un senti- ment: le besoin de sécurité", Annales. Economies Soctétés Civilisations, Paris, 1956. Le problème de l'incropance au xve siècle. La religion de Rabelais, París, 1968.

Febvre, Lucien y otros, la sensibilité dans l'bistoire, Brionne, 1987.

-Flottes, Pierre, El inconsctente en la bistoria, Guadarrama, Madrid, 1971.

-Foucault, Michel, Vigilary castigar. Nactmtento de la prisión, Siglo XXI Editores de España, Madrid, 1990.

-Freund, Gisèle, La fotografía como documento social, Gustavo Gili, Barcelona, 1976.

-Friedlander, Saul, Histoire et psychanalyse. Essat sur les possibilités et les $1 t$. mites de la psycbobistoive, París, 1975.

-Furet, F. y A. Fontana, "Histoire et linguistique", Livme et societé dans la France du xvine stècle; vol. II, La Haya, 1970.

-García Cárcel, R., "La muerte en la Barcelona del Antiguo R'égümen (aproximación metodológica)", II Coloquio de metodología bistórica aplicada, Santiago de Compostela, 1984.

-Gasparri, G., Crimes et chatiments en Provence au temps du rot René. Procédure criminelle au 15 er siècle, París, 1989.

la societat medieval", Revista d'Historia Medieval, núm. 1, 1990.

-Geremek, B., La piedad y la borca: bistoria de la miseria y la caridad en Europa, Madrid, 1989.

-Gergen, K. J. y M. M. Gergen (comps.), Historical social psychology, Hillsdale, 1984.

-Giesley, R. E., Le roi ne meurt jamais, París, 1987.

-Gilmore, W, Psycbobistortcal inquiry: a comprebensive researcb bibliogyaply, Nueva York, 1984.

-Ginzburg, C., El queso y los gusanos. El cosmos, según un molinero.del siglo XVI, Muchnik Editores; Barcelona, 1982.

-Girard, R., La violence et le sacré, 1972. 


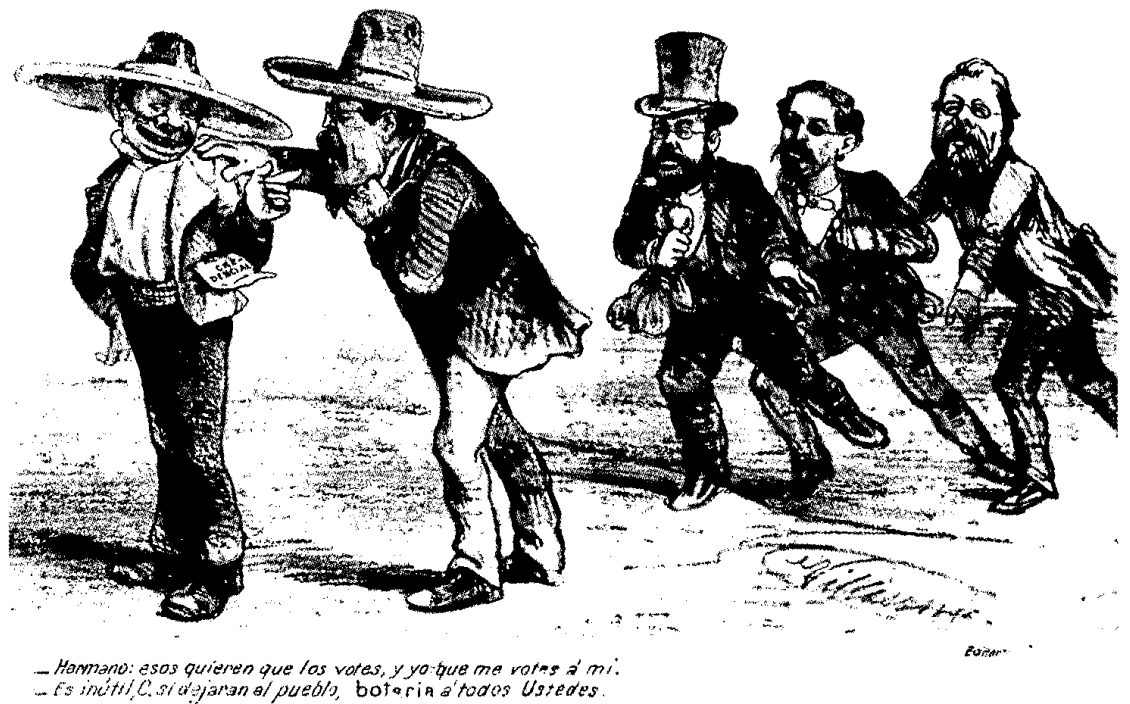

-Guiance, A., Muertes medievales, mentalidades medievales. Un estado de la cuestión sobre la historia de la muerte en la Edad Media, Buenos Aires, 1989.

-Hobsbawm, E. J., y T. Ranger (comps.), Linvent de la tradicio, Barcelona, 1988. , Image et bistoire: Actes du Coloque de Paris-Censier, mai 1986, París, 1987.

Jodelet, Denise (dir.), Les representations sociales, París, 1989.

Joutard, Philipe, "L'histoire dans l'imaginaire colectif", L'Arc, núm. 72, 1978, pp. 38-42.

, Esas voces que nos llegan del pasado, Fondo de Cultura Económica, México, 1986.

-Julia, Santos, Historia social/sociología bistórica, Madrid, 1989.

-Kantarowicz, E. H., Los dos cuerpos del rey. Un estudio de teología política medieval, Madrid, 1985.

-Kren, G. M., y H. Rapaport, Varietes of psycbobistory, Nueva York, 1985.

-Labrousse, E. y otros, Órdenes, estamentos y clases, Madrid, 1978.

-Le Goff, Jacques, La civilisation de l'Occident médiéval, París, 1964.

rio, Madrid, 1985. , El nacimiento del purgato- "El historiador y el hombre cotidiano", Tiempo, trabajo y cultura en el Occtdente medieval, Taurus, Madrid, 1983.

, L'imaginaire médiéval. Essais, París, 1985.

-Le Roy Ladurie, E., Montaillou, aldea occitana de 1294 a 1324, Madrid, 1981.

-Lefebvre, Henri, Critique de la vie quotidienne, 3 vols., París, 1946-1981. 
-Levi, Giovanni, La berencia inmaterial, Madrid, 1991.

-Lévy-Bruhl, Lucien, Les fonctions mentales dans les sociétés inférieurs, 1910.

, La mentalité primitive, 1922.

-Lloyd de Mause (comp.), A bibliograpby of psychobistory, Nueva York, 1975.

tory, Nueva York, 1982. Foundations of psychobis-

-López, R. L., Oviedo: muerte y religiosidad en el siglo XVII (un estudio de mentalidades colectivas), Oviedo, 1985.

-Lorenzo Pinar, L., Actitudes religtosas ante la muerte en Zamora en el siglo xVI: un estudio de mentalidades, Zamora, 1989.

-Mamardashvili, Merab, "Análisis de la conciencia en los trabajos de Marx", Ciencias Sociales, núm. 2, 1987.

-Mandrou, R., Introducción a la France moderne, 1500-1640, Paris, 1961.

, "L'histoire des mentalités", Enciclopedia Universalis, vol. vII, 1968.

-Manselli, R., La religión populatre au Moyen Age. Problèmes de mètbode et d'bistoive, París-Montreal, 1975.

-Martin, M. A. y 1. Bazani, "La idea de la muerte renacentista a través de los sepulcros de la Iglesia de San Pedro de Vitoria", Congreso de filosofía, ética y religión, Vitoria, 1988.

-Martines, L., Violence and civil disorder in italian cities, 1200-1500, Berkeley, 1972.

-Martínez Gil, F., "Muerte y sociedad en la España de los Austrias", tesis doctoral, Universidad Complutense, Madrid, 1990.

-Mentalités et représentations politiques. Aspects de la recbecber, Roubaix, 1989.

-Mitre Fernández, E., La muerte vencida: imágenes e bistoria en el Occidente medieval (1200-1348), Madrid, 1988.

-Molho, Maurice, "Linguistique et histoire", Mélanges de la Casa de Velázquez, vol. XII, 1976.

-Moreta, S., Malbechores-feudales. Violencia, antagonismos y alianzas de clases en Castilla, siglos XIII-XIV, Madrid, 1978.
Mojen Age, París, 1990.

-Moya, M. y M. Armengol, "La consciència de la mort: la seguretat dels testaments", L'Avenc, núm. 78, 1985.

-Muchembled, Robert, La violence au village. Soctabilité et comportement populaines en Artois du xve au Xvile siècle, Bélgica, 1989.

-Munné, Frederic, Psicologías sociales manginadas. La linea de Marx en la psicología social, Barcelona, 1982.

- Olabarri, Ignacio, La bistoriografía en Occidente desde 1945, Pamplona, 1985.

-Pastor, Reyna, "Diego Gelmiriz: una mentalidad al dia", en Conflictos sociales y estancamiento económico en la España medieval, Barcelona, 1973.

-Patlagean, Evelyne, "L'histoire de l'imaginaire", La Nouvelle Histoire, París, 1978 (Bilbao, 1988).

-Pinillos, José Luis, "El problema de las mentalidades", Creencias, actitudes $y$ valores. Tratado de psicología general, núm. 7, Madrid, 1989.

-Portela, E. y M. Nuñez (comps.), La idea y el sentimiento de la muerte en la bistoria y en el arte de la Edad Media, Santiago de Compostela, 1988.

-Portela, E. y M. C. Pallares, "Muerte y sociedades en la Galicia medieval (siglos XII-XIV)", Anuario de Estudios Medievales, núm. 15, 1985.

-Raynaud, Ch., La violence au Moyen Age, xulle-XVe, París, 1990.

-Reich, Wilhelm, La psicología de masas del fascismo (1933), México, 1973.

-Rey Castelao, O., "El clero urbano compostelano a fines del siglo XVII: mentalidades y hábitos culturales", La bistoria social de Galicia en sus fuentes de protocolos, Santiago de Compostela, 1981.

-Riego, Bernardo, "La fotografía como fuente de la historia contemporánea", Jornadas La imatge i la recerca bistorica, Gerona, 1990.

-Robin, Regine, Histoire et linguistique, Paris, 1973. 
-Rucquoi, A., "Le corps et la mort en Castille aux xuve et XVe siècle", Razo, núm. 2, 1981.

-Ruguiero, G., Patrici e malfattori. La violenza a Venezia del primo Rinascimiento, Bolonia, 1982.

litês, núm. 3, 1989. "Violence sexuelles", Menta-

-Ruiz, Teófilo, "Une royauté sans sacré: la monarchie castillane du Bas Moyen Age", Annales. Economies Sociétés Civilisations, núm. 3, París, 1984.

-Schmitt, Jean-Claude, La berejía del Santo Lebrel. Guinefort, curandero de niños desde el siglo XVII, Muchnik Editores, Barcelona, 1984.

"Introducció a una história

de l'imaginari medieval", El mon imaginari i el mon meravellós a l'Eckat Mitjana, Barcelona, 1986.

, La raison des gestes dans l'Occident mediéval, Gallimard,' París, 1990.

-Sperber, Dan, El simbolismo en general. Temas antropológicos, Barcelona, 1978.

-Stengers, I., D'une science a l'autre. Des concepts nomades, París, 1987.

-Szaluta, La psychobistoire, París, 1987.

-Thomas, K., Religton and the decline of magic, Londres, 1971.

La voz del pasado. Historia oral, Valencia, 1986.
Historia Social, núm. 3, 1989.

-Tilly, C.; "Revolution and collective violence", Handbook of Political Sctence, Massachussetts, núm. 3, 1975.

Tuñón de Lara, M., Once ensayos sobre la bistoria, Madrid, 1976. , "Por una historia de Historia 16", Historia 16, núm. 181.

-Valdeon, Julio, "Quince años de historiografia española", Historia 16 , núm. 181, 1991.

-Vaquero Iglesias, J. A., "Muerte e ideologia en Asturias (siglo XIX)", tesis doctoral, Universidad de Oviedo, 1989.

-Vicquers, B. (comp.), Mentalidades ocultas $y$ científicas en el Renactmiento, Madrid, 1990.

-Vovelle, Michel, La mort et l'Occident de 1300 a nos jours, Paris, 1982.

$\longrightarrow$, "iHay un inconsciente colectivo?", Ideologias y mentalidades, Barcelona, 1985.

- Wallon, Henri, La mentalité primitive et celle de l'enfant, 1928.

-Wickman, Chris, "Comprender lo cotidiano: antropología social e historia social", Historia Social, núm. 3, 1989 (1a. edición en italiano, 1985).

-Wolfromm, Jean-Didier, "La sociología de la vida cotidiana", Debats, núm. 10, 1984 .

, "Quaranta anos de vida cotidiana", A Nova Historia, Lisboa, 1986. 